\title{
FATIGUE CRACK PROPAGATION IN
}

\section{SINGLE CRYSTAL CMSX-2 AT ELEVATED TEMPERATURE}

\author{
Bruce F. Antolovich, $\Lambda$ shok Saxena and Stephen D. Antolovich \\ Graduate Student, Professor, Professor and Director respectively, \\ School of Materials Engineering and Mechanical Properties Research Lab \\ Georgia Institute of Technology \\ Atlanta, Georgia 30332-0245
}

\begin{abstract}
The fatigue crack propagation behavior of the nickel base superalloy CMSX-2 in single crystal form was investigated. Tests were conducted for two temperatures $\left(25\right.$ and $\left.700^{\circ} \mathrm{C}\right)$, two orientations ([001][110] and [001][010]), and in two environments (laboratory air and ultra-high vacuum 10-7 torr). Following FCP testing, the fracture surfaces were examined using scanning electron microscopy. Transmission electron microscopy was used to determine the size and shape of the $\gamma^{\prime}$ precipitates.

FCP rates were found to be relatively independent of the temperature, environment and orientation when correlated with the conventional mode I stress intensity factor. Examination of the fracture surfaces showed two distinct types of fracture. One type was characterized by $\{111\}$ fracture surfaces which were inclined relative to both the loading and crack propagation directions. These features, while clearly a result of the fatigue process resembled cleavage fractures along $\{111\}$ planes. Such features were observed at 25 and $700^{\circ} \mathrm{C}$; they were the only features observed for the $25^{\circ} \mathrm{C}$ tests. The second type had a macroscopically dull loading appearance, was microscopically rough and grew normal to the loading axis. This feature was seen on the specimens tested at $700^{\circ} \mathrm{C}$ (in both air and vacuum) and had a similar appearance to conventional fatigue fractures. Although in this region the crack plane was macroscopically normal to the loading direction, it deviated microscopically to avoid shearing the $\gamma^{\prime}$ precipitates. In view of the complex crack growth mechanisms, mixed fracture modes, and lack of any difference in FCP rates, it is hypothesized that the correlation between FCP rates and stress intensity parameter is probably coincidental. The implications for life prediction of higher temperature turbine components based on conventional fracture mechanics are significant and should be further investigated.
\end{abstract}




\section{Introduction}

Nickel base superalloys have been the traditional material of choice for the turbine section of modern jet engines due to their excellent high temperature mechanical properties. However, their resistance to stress rupture is significantly degraded in the presence of an oxidizing environment. It has been suggested that diffusion of oxygen along grain boundaries is the primary mechanism of this degradation. Blade coatings, directional solidification (DS), and single crystal (XL) are processes that have been developed in an effort to eliminate these grain boundary effects by either isolating, favorably orienting or removing the grain boundaries. However, XL and DS blades introduce the problem of anisotropic behavior into engineering analysis for creep, low cycle fatigue (LCF) and fatigue crack propagation (FCP).

While creep and LCF resistance are primary design considerations for turbine blades, the durability requirements introduced under Engine Structural Integrity Program (ENSIP) makes FCP bchavior a property that merits consideration. However, due to elastic and plastic anisotropy, characterization of FCP is not straight forward. In this paper, the FCP behavior of CMSX-2 in single crystalline form is studied with respect to mechanisms of crack extension, effects of orientation, and the significance of $\mathrm{K}$ as a characterizing parameter for FCP in this class of material.

\section{Experimental Procedure}

\section{Material}

CMSX-2 is a modified MAR-M 247 nickel-base superalloy for use as a single crystal. The nominal composition is given in Table I.

Table I - Nominal Composition of CMSX-2 (w/o)

\begin{tabular}{|c|c|c|c|c|c|c|c|}
\hline $\mathrm{Al}$ & $\mathrm{Co}$ & $\mathrm{Cr}$ & $\mathrm{Ti}$ & $\mathrm{Ta}$ & $\mathrm{W}$ & $\mathrm{Mo}$ & $\mathrm{Ni}$ \\
\hline 5.6 & 4.6 & 8 & 1.1 & 6 & 8 & 0.6 & Balance \\
\hline
\end{tabular}

The specimens used in this study were austenitized at $1315^{\circ} \mathrm{C}$ for 3 hours and subsequently air cooled. The precipitation treatment consisted of heating to $1050^{\circ} \mathrm{C}$ for 16 hours followed by air cooling. This was then followed by ageing at $850^{\circ} \mathrm{C}$ for 24 hours followed by air cooling. These heat treatments were developed by ONERA to create regularly spaced cuboidal $\gamma^{\prime}$ precipitates with sides that are roughly $0.5 \pm 0.1 \mu \mathrm{m}$ in length. This precipitate arrangement has been shown to enhance creep properties[1]. The volume fraction of $\gamma^{\prime}$ precipitates is approximately $65 \%$.

\section{Mechanical Testing and Fracture Surface Observation}

Plastic deformation and fracture in Ni-base superalloy single crystals is dominated by the crystallographic orientation. Cracking frequently occurs on combinations of $\{111\}$ and $\{100\}$ type planes. [2-4] In order to investigate the effects of orientation on FCP behavior, tests were conducted on CT specimens with two different crystallographic orientations, Fig. 1. Tests were conducted in laboratory air at room temperature and at $700^{\circ} \mathrm{C}$ in air and in vacuum of $10^{-7}$ torr.

Crack length was monitored continuously during the tests using the electro-potential drop technique[5]. Crack length (a) as a function of the number of cycles (N)

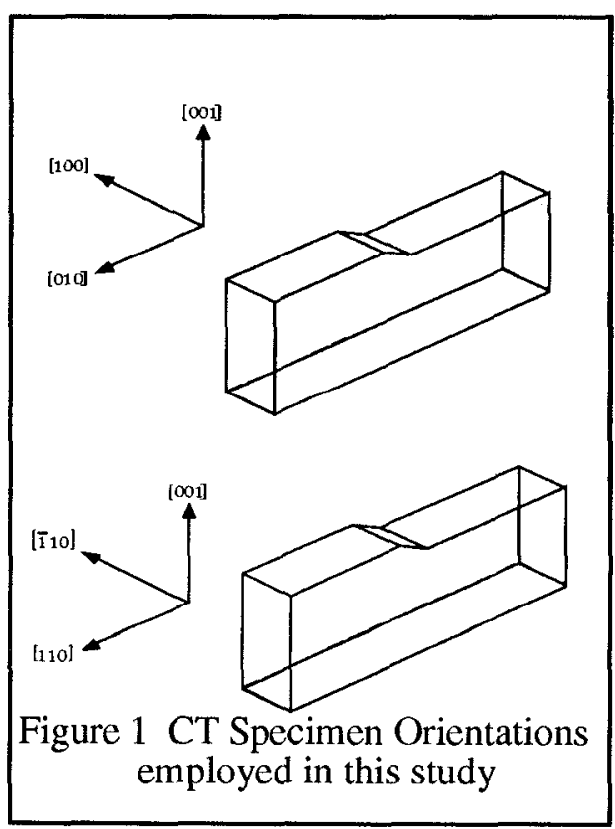


was rccordcd. Plots of $\mathrm{da} / \mathrm{N}$ vs $\Delta \mathrm{K}$ were generated using the procedure described in ASTM E647[6].

Following FCP testing, the fracture surfaces were examined using scanning electron microscopy (SEM). These results are discussed in the next section.

\section{$\underline{\text { Results and Discussion }}$}

\section{Crack Growth Rate vs Delta K}

Figure 2 shows the experimental results presented using the traditional stress intensity factor, $\mathrm{K}$, for correlating da/dN. There appears to be little systematic difference in the crack growth rates between the various orientation-temperature-environment combinations. Any differences in crack growth rates resulting from the test variables are masked by the spread in the data.

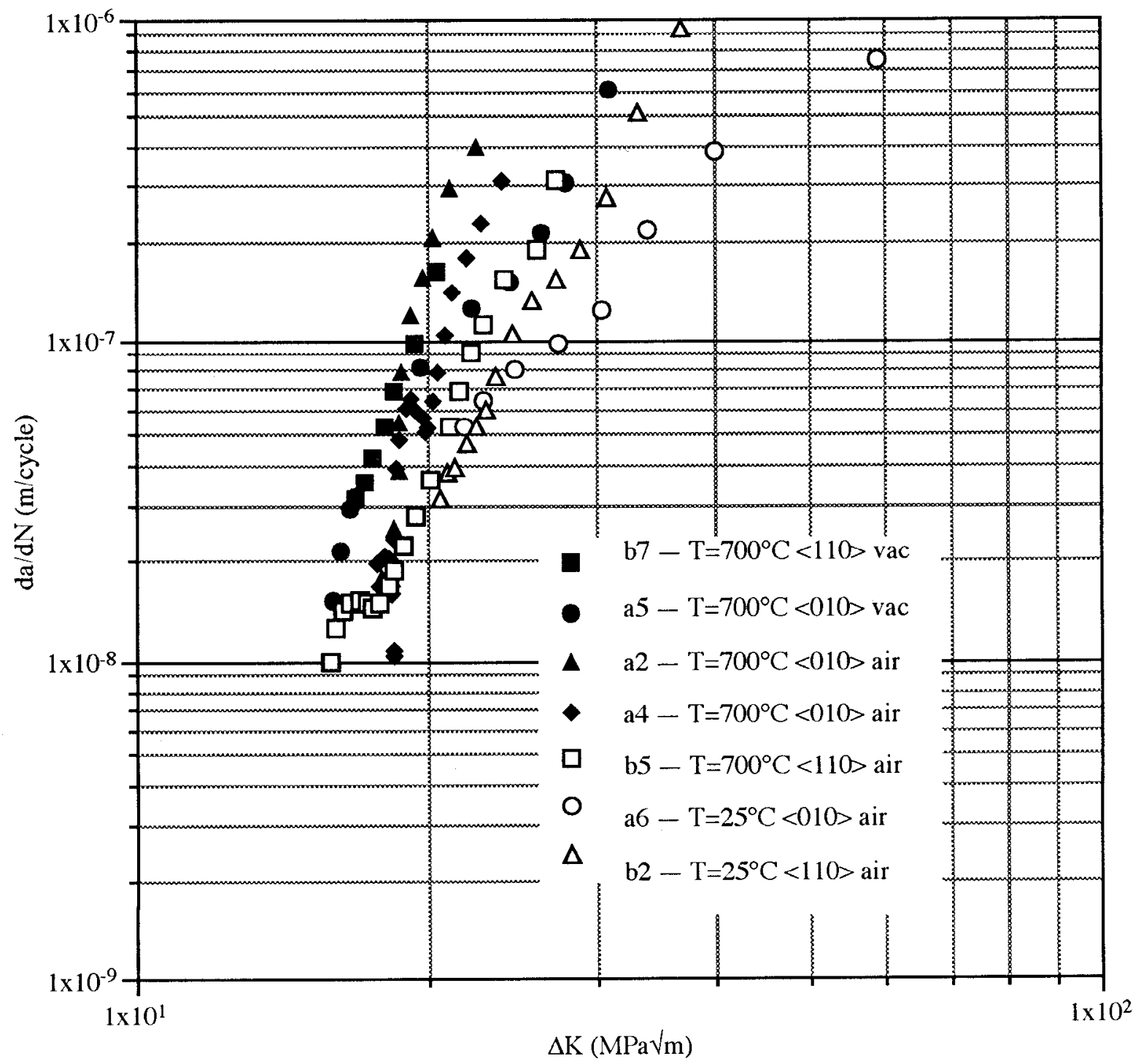

Figure 2 FCP rates for specimens with [010] and [110] orientations tested in air and vacuum at $700^{\circ} \mathrm{C}$ and air at $25^{\circ} \mathrm{C}$

The applicability of $\mathrm{K}$ which is based upon the assumptions of isotropy and self-similar crack growth is not immediately obvious. Moreover, the cracks in these specimens were inclined to the plane normal to the loading axis and the values of $K_{I}$ are different from those with the crack 
growing normal to the applied load. Despite these analytical problems, da/dN appears to correlate well with $\Delta \mathrm{K}$. There may be several reasons for this. For example, $\mathrm{K}$ values for inclined cracks in CT specimens were numerically determined by Cruse and were found to be approximately equal to those for cracks growing normal to the loading axis[7]. It was shown that for cracks deviating up to $30^{\circ}$ from the plane normal to the loading axis, the value of $\mathrm{K}$ was virtually unchanged. Another reason for the apparent good correlation may be that duplicate specimens under each condition were tested using similar load levels. Therefore, the good agreement between $\mathrm{da} / \mathrm{dN}$ and $\Delta \mathrm{K}$ may simply be coincidental.

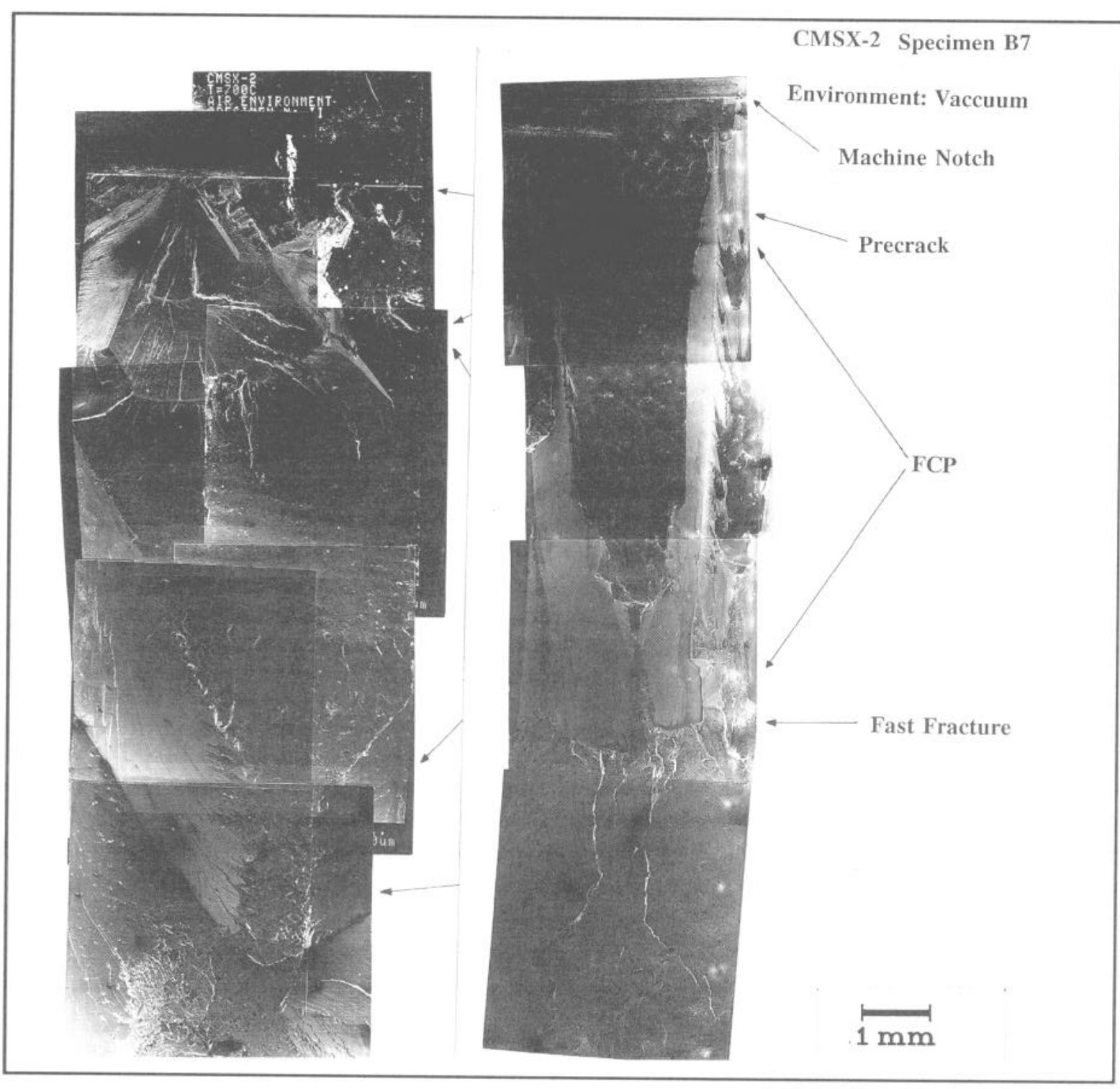

Figure 3 Photomicrographs showing fracture surfaces of tested specimens with [010] and [110] orientations

\section{Fracture Surface Observations}

The fracture surfaces of tested specimens showed significantly different morphologies depending upon the combination of temperature, environment and specimen orientation. Greater differences in the morphologies appears to result from changing specimen orientation than from changing the environment. Specimens tested at $700^{\circ} \mathrm{C}$ in which the width was parallel to [010] exhibited fracture surfaces with two characteristic regions: 
i) regions of the fracture surface that were inclined to the load axis and width of the specimen which were flat and shiny in appearance

ii) regions in which the fracture surfaces were normal to the loading axis and which were dull and rough in appearance.

In the first region, neither the direction of crack propagation nor the plane on which the crack propagated appear to be normal to the direction of applied loading. The shiny inclined sections were slanted both relative to the thickness and the width of the specimen. The dull surfaces have a "wavy" appearance. The troughs and peaks of these 'waves' are parallel to the specimen thickness in the [001] direction. The wavelength corresponds to the dendrite dimensions.

Specimens for which the width was parallel to [011] also exhibited similar fracture surface features. The two types of surfaces were:

i) flat and shiny regions inclined at an angle relative to the thickness of the specimen but not to the width and

ii) regions in which the fracture surfaces were normal to the loading axis and which were dull and rough in appearance.

Photomicrographs of the fracture surfaces of specimens tested at $700^{\circ} \mathrm{C}$ for both orientations are shown in Fig 3. There appear to be two distinct regions for each orientation; one that is flat and shiny and the other that resembles a traditional polycrystalline fatigue fracture surface. Measurement of the angles of the flat planar regions indicates that these are $\{111\}$ type planes. Their appearance is shiny and they appear distinct from the regions of fracture which are normal to the loading axis and have the appearance of conventional fatigue fracture. The shiny flat regions were further examined at higher magnifications as shown in Fig. 4 and were shown to retain their planar featureless appearance. While these features are similar to those observed in the overload fracture region, Fig. 5, there can be little doubt that they were formed by a fatigue process. It is also important to note that the two types of fractures in the specimens with different orientations appear to be quite similar to each other. This suggests that the same basic mechanisms of crack advance operate for both specimen orientations, as discussed in the following section.

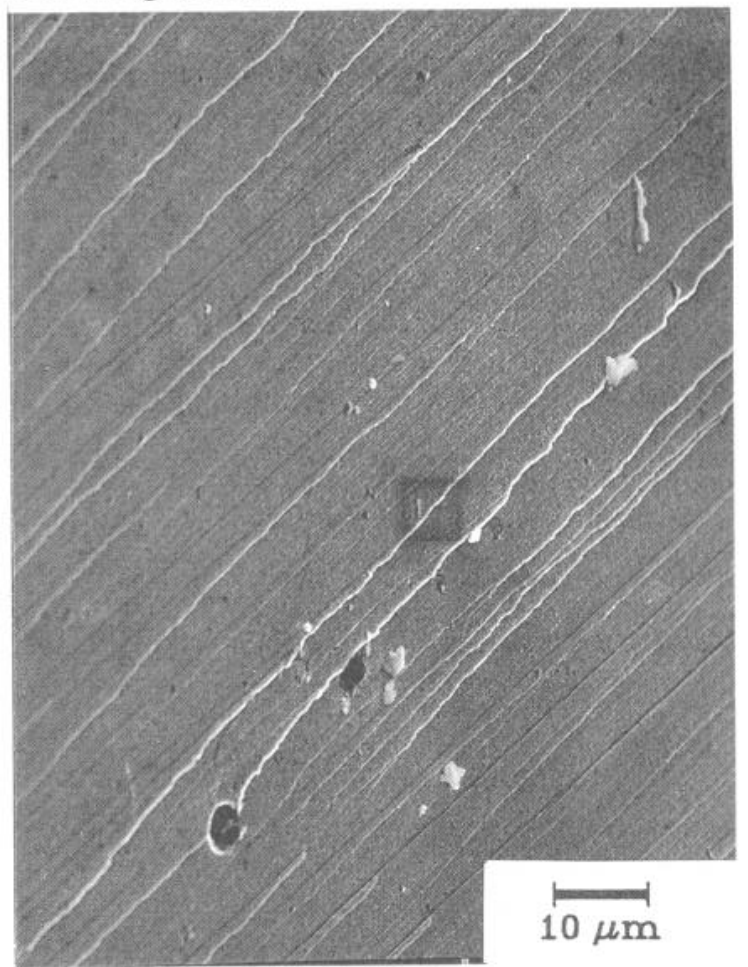

Figure 4 Planar fatigue crack

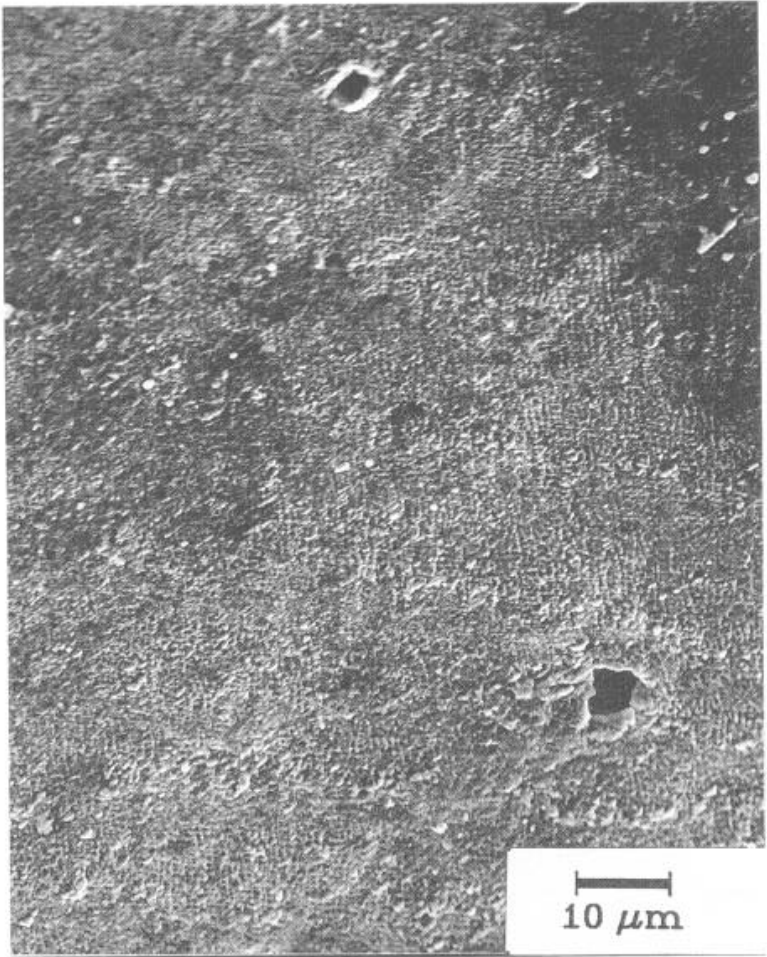

Figure 5 Fast fracture surface 
At room temperature, only flat, shiny, fracture surfaces were observed. For specimens with [110] parallel to the width, the intersections of these flat regions were parallel to the width. Clearly the planes were of the type $\{111\}$ while the intersections were parallel to [110]. A low magnification view of the room temperature fracture surface is shown in Fig. 6 while a higher magnification SEM photomicrograph is shown in Fig.7. It is interesting that at higher magnifications, microscopically, the flat regions formed at room temperature appear to be rougher than those formed at $700^{\circ} \mathrm{C}$ in either air on vacuum. This roughness probably reflects the fact that the $\gamma^{\prime}$ is softer at $25^{\circ} \mathrm{C}$ than at $700^{\circ} \mathrm{C}$. It is interesting to note that the fracture surface contains sheared $\gamma^{\prime}$ particles and there is no tendency whatsoever for the crack to avoid the precipitates.

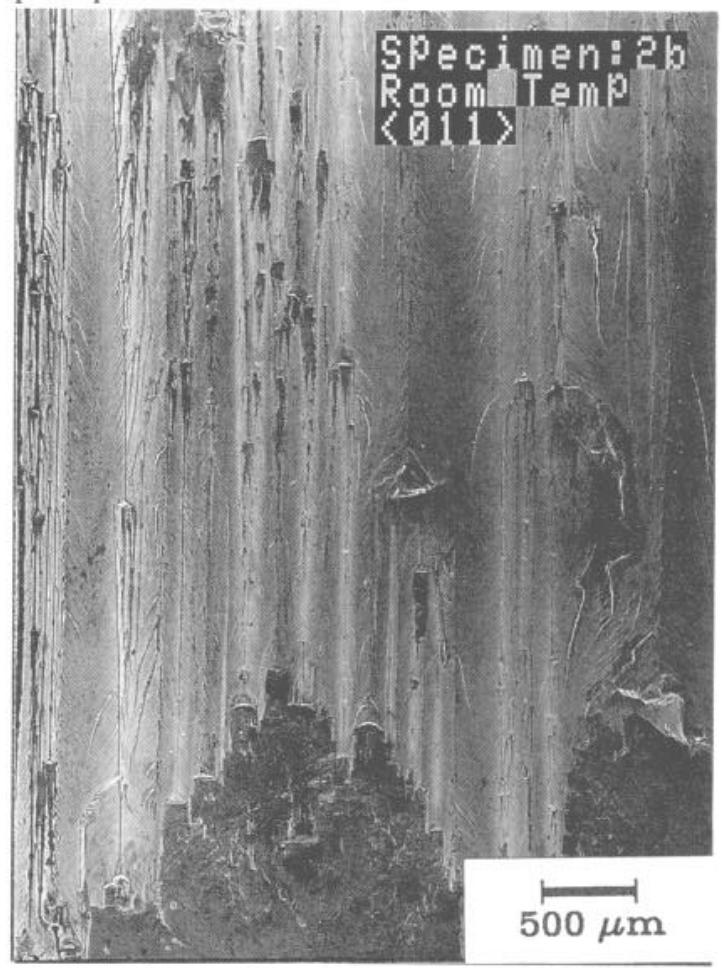

Figure 6
Room temperature fracture surface

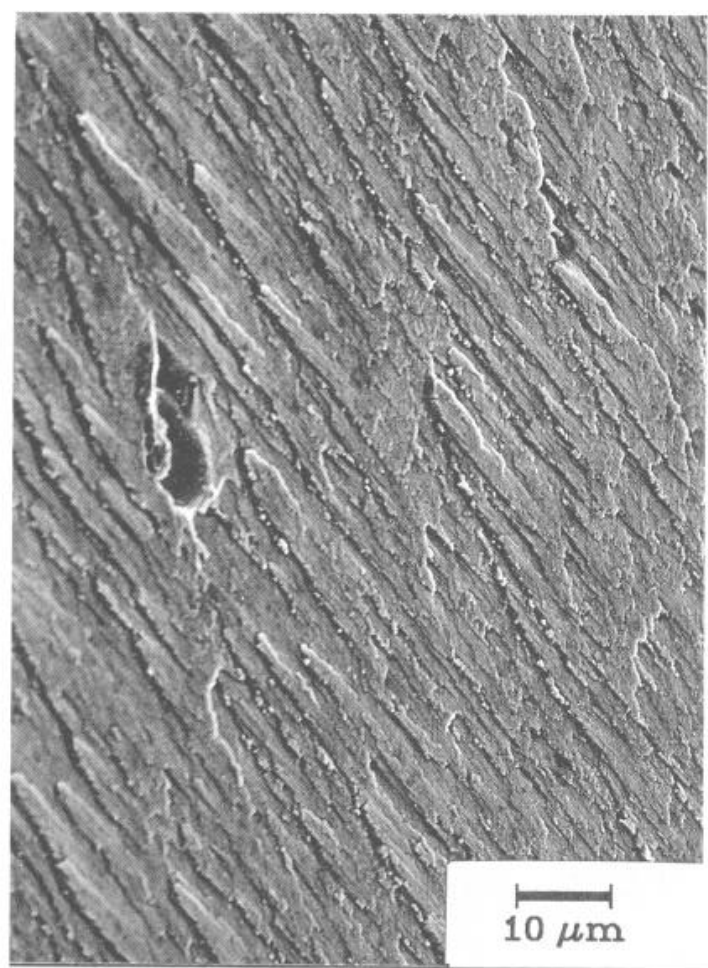

Figure 7
High magnification

of fracture surface shown in Figure 6

These differences in fracture surface appearance seem to correlate very well with what is known about deformation in Ni-base alloys. At low temperatures, it is well established that the precipitates are relatively weak (at least compared to the peak strength at higher temperature) and easily sheared. Deformation on $\{111\}$ is very much easier than on $\{100\}$ so it would be anticipated that fracture surfaces would be of the $\{111\}$ type and would contain evidence of sheared precipitates. At high temperatures, on the other hand, it is well known that the $\{111\}$ planes in the precipitates become progressively harder $[8,9]$. Thus at some relatively high temperature, deformation can take place more easily on $\{100\}$ planes $[8,9]$ than on $\{111\}$ planes. For these reasons, it is quite clear that there will be a transition from $\{111\}$-type deformation to $\{100\}$-type deformation. To the extent that cracking is dictated by deformation in front of the crack tip, one would also expect the fracture surface to be broadly reflective of these mechanisms. That is to say, both $\{111\}$ facets and $\{100\}$ planes should be observed. An alternative explanation for the $\{100\}$ cracking at $700^{\circ} \mathrm{C}$ is offered in the following paragraphs.

Fracture surfaces of specimens from both orientations have zones in which the cracking does not appear to be macroscopically associated with any particular set of crystallographic planes. The cracks in these regions appear to propagate on the (001) plane which is normal to the loading axis. This is in apparent contradiction with the proposed model which is based on the assumption that cracking occurs only on the $\{111\}$ planes. This apparent contradiction can be explained. It is proposed that crack growth in these fatigue regions is also crystallographic in 
nature and does in fact occur locally on a combination of $\{111\}$ and $\{100\}$ type planes. Damage introduced by dislocation movement due to cyclic loading can accumulate on several parallel but not necessarily adjacent $\{111\}$ planes between adjacent $\gamma^{\prime}$ precipitates. This damage can lead to a series of cracks growing on parallel $\{111\}$ planes. As the crack propagates along the $\{111\}$ type plane, it will run into one of the $\gamma^{\prime}$ precipitates and stop growing because of the high strength of the precipitate at this temperature. The $\gamma$ precipitate faces are parallel to $\{100\}$ to minimize the strain energy. Since the dislocations do not shear the hard $\gamma^{\prime}$, a build up in dislocation density at the precipitate interface is expected. The crack then finds an easy path to follow along the damaged $\gamma$ interface. The SEM stereo pair in Fig. 8 clearly shows the cracks

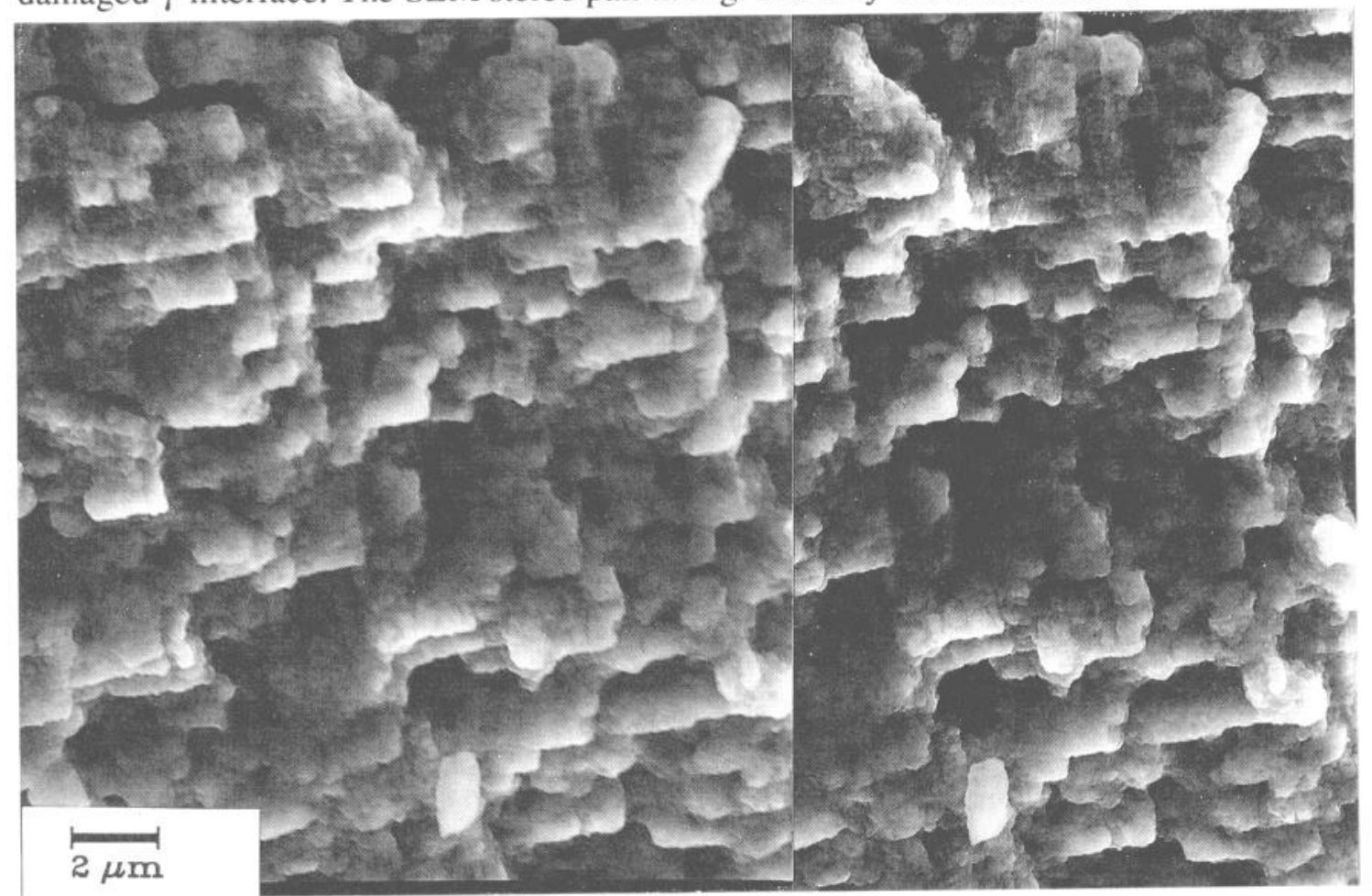

Figure $8 \quad$ Stereo pair showing cracks avoiding $\gamma^{\prime}$ precipitates

deviating around a series of cube faces which correspond in size and orientation to the $\gamma^{\prime}$ precipitates. Therefore, it appears possible that the crack deviates from the $\{111\}$ planes and propagates along the $\{100\}$ plane at the interface between the austenitic matrix and the $\gamma^{\prime}$ precipitates. It is unclear at this point whether the crack propagates along this interface as a monotonic cleavage event or as a series of microcracks on $\{111\}$ type planes that join to give a nominal $\{100\}$ plane of propagation. Figure 9 shows the proposed crack advance mechanism in the fatigue 
region. Secondary cracks were also found to avoid cutting the $\gamma^{\prime}$ precipitates.

It is important to note that slip bands in front of more than one $\gamma$ precipitate can be operating, Fig. 9. The stress fields activating the slip bands due to the presence of a crack decrease in magnitude with distance from the crack tip as predicted by the anisotropic field equations. Therefore, the slip bands that intersect the plane normal to the loading direction that originates at the crack tip will be more active than those that don't. This results in higher dislocation densities in these slip bands and hence lower normal forces required to propagate the crack. Therefore the slip bands which intersect this plane are expected to form cracks which will ultimately be linked by cracks propagating along the $\{100\}$ plane at the interface between the matrix and the $\gamma^{\prime}$ precipitates.

Secondary cracking will occur by the same mechanism. The only difference between the secondary and primary cracking is that the direction of crack propagation for secondary cracks tends to reduce the magnitude of the stress fields as predicted by the field equations more quickly than for the case of the primary crack.

It has been previously proposed that the plane and direction of fatigue crack growth in anisotropic single crystals can be predicted by finding a combination of primary slip plane and direction for which the product of the normal stress acting on the plane and the shear stress in the direction of the Burgers vector has the maximum absolute value[10]. The magnitude of normal and shear stresses on primary slip planes and directions can be found by using the field equations for the stress fields ahead of the crack in anisotropic bodies[11].

$$
\tau_{\mathrm{ij}}=\frac{\mathrm{K}_{\mathrm{I}}}{\sqrt{2 \pi \mathrm{r}}} f_{\mathrm{ij}}(\mu, \theta)
$$

The stresses predicted by the above equations are then transformed to the appropriate normal and shear stresses using standard tensor transformations.

$$
\tau_{\alpha \beta}=a_{\alpha i} a_{\beta j} \tau_{i j}
$$

where $\tau_{\alpha \beta}=$ transformed stress tensor

$$
\begin{aligned}
\mathrm{a}_{\alpha \mathrm{i}}, \mathrm{a}_{\beta \mathrm{j}} & =\text { direction cosines } \\
\tau_{\mathrm{ij}} & =\text { original stress tensor }
\end{aligned}
$$

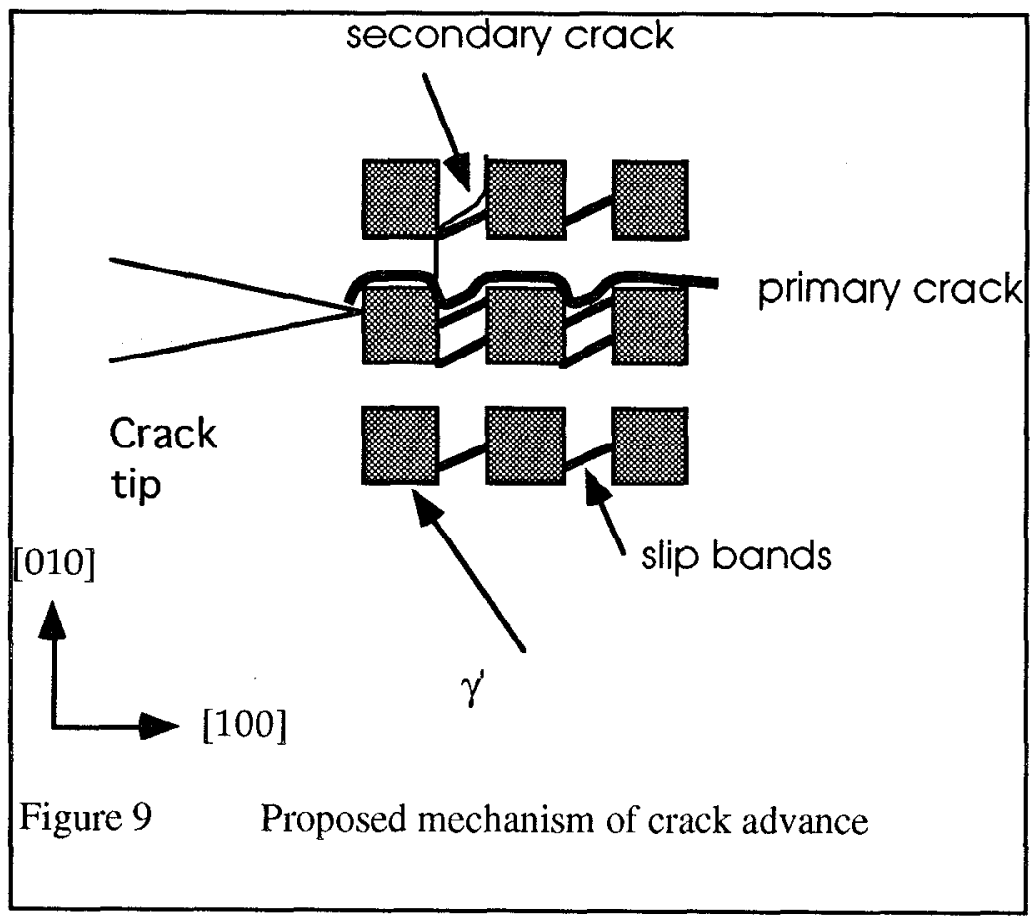

The product of the normal and shear stresses on each of the slip planes but normalized by $\left(\frac{\mathrm{K}^{2}}{2 \pi \mathrm{r}}\right)$ are shown in Table II. Table II shows the trigonometric function in the equations for normal stresses and shear stresses and their product for a [001] loading direction for all $\{111\}<110>$ type slip systems in a cubic crystal. 
Table II — Normal, Shear stress products

\begin{tabular}{lcccc}
\hline $\begin{array}{l}\text { slip } \\
\text { plane }\end{array}$ & $\begin{array}{c}\text { Burgers } \\
\text { vector }\end{array}$ & $\begin{array}{c}\text { normal } \\
\text { stress }\end{array}$ & $\begin{array}{c}\text { shear } \\
\text { stress }\end{array}$ & Product \\
\hline$(111)$ & {$[\overline{1} 10]$} & 0.33 & 0.00 & 0.000 \\
$(111)$ & {$[01 \overline{1}]$} & 0.33 & -0.41 & -0.135 \\
$(11 \overline{1})$ & {$[10 \overline{1}]$} & 0.33 & -0.41 & -0.135 \\
$(1 \overline{1} 1)$ & {$[10 \overline{1}]$} & 0.33 & -0.41 & -0.135 \\
$(1 \overline{1} 1)$ & {$[110]$} & 0.33 & 0.00 & 0.000 \\
$(1 \overline{1} 1)$ & {$[0 \overline{1} \overline{1}]$} & 0.33 & -0.41 & -0.135 \\
$(11 \overline{1})$ & {$[\overline{1} 0 \overline{1}]$} & 0.33 & 0.41 & 0.135 \\
$(11 \overline{1})$ & {$[0 \overline{1} \overline{1}]$} & 0.33 & 0.41 & 0.135 \\
$(11 \overline{1})$ & {$[\overline{1} 10]$} & 0.33 & 0.00 & 0.000 \\
$(\overline{1} 11)$ & {$[110]$} & 0.33 & 0.00 & 0.000 \\
$(\overline{1} 11)$ & {$[01 \overline{1}]$} & 0.33 & -0.41 & -0.135 \\
$(\overline{1} 11)$ & {$[10 \overline{1}]$} & 0.33 & -0.41 & -0.135 \\
& & & & \\
\hline
\end{tabular}

Because both orientations tested in this study share a common [001] loading axis, the crack growth is predicted to occur along the same plane and direction for both orientations. Therefore, the fundamental fatigue crack growth rates are also predicted to be the same for both orientations. However, in the case of the [011] orientation, the predicted direction of crack growth is parallel to the length of the specimen while in the [010] orientation, the predicted crack growth direction is at an angle relative to the side of the specimen. Therefore, one might reasonably expect a greater influence of altered stress states as the crack grows from a region of plane strain to a region of plane stress for the [010] orientation than the [011] orientation. Since the dominant cracking mechanisms are the same for both orientations, this can also be another reason why the FCP rates, when correlated with $\Delta \mathrm{K}$, are also the same for both orientations.

The above models of fatigue crack growth appear to explain the differences in the macroscopic crack growth modes observed for specimens of both orientations. The crack growth in single crystals does not occur in a self-similar fashion or under purely mode I conditions. Therefore, the use of $\mathrm{K}$ to correlate fatigue crack growth in single crystals is not recommended. However, if the proposed models are confirmed by more data, it may be possible to predict the FCP rates in single crystal materials if the orientation of the crystals to the loading axis is known. A mathematical model which will be undoubtedly more complex than the Paris equation and which uses an appropriate forcing function can be developed to predict this behavior. This remains a goal for future studies.

\section{Conclusions}

1. FCP in single crystals of CMSX-2 appears to correlate with K. However, this correlation may be more fortuitous than representative of a genuine relationship. Additionally, attempts to correlate FCP rates with $\mathrm{K}$ do not include the effects of combined mode loading and it is clear from the fracture surface observations that more than one mode of crack extension is opcrating.

2. Fatigue crack extension in single crystal CMSX-2 occurs by a single mechanism at $25 \mathrm{C}$ (cracking on $\{111\}$ ) and by combination of mechanisms at $700 \mathrm{C}$ (cracking on $\{111\}$ and $\{100\})$.

3. The crack extension processes are reflective of the fundamental deformation mechanisms that occur in $\gamma^{\prime}$ as a function of temperature. 
4. At $700^{\circ} \mathrm{C}$ in certain regions, fatigue cracks grow macroscopically on planes normal to the applied load and microscopically on parallel $\{111\}$ planes in the austenitic matrix and on $\{100\}$ planes at the interface between the matrix and the $\gamma$ precipitates.

5. In attempting FCP data correlation and life prediction of Ni-base superalloy components at high temperature, caution is recommended in the use of $\mathrm{K}$. Further work is required to develop a true forcing function on which such correlations and calculations can be based.

\section{Acknowledgements}

We would like to acknowledge ONERA ( $\mathrm{Mr} \mathrm{T}$. Khan and $\mathrm{Mr} \mathrm{P}$. Caron) for supplying specimens used in this study. We would also like to acknowledge help in the experimental program from Thibaut Robin, École Centrale, Paris, France.

\section{$\underline{\text { References }}$}

1. P. Caron, Y. Ohta, Y.G. Nakagawa and T. Khan, "Creep Deformation Anisotropy in Single Crystal Superalloys," Superalloys 1988, eds. D.N. Duhl et al. , (Warrendale, PA: TMS-AIME, 1988) 215-224

2. M. Dollar and I.M. Bernstein, "The Effect of Temperature on the Deformation Structure of Single Crystal Nickel Base Superalloys," Superalloys 1988, ed. D.N. Duhl et al., (Warrendale, PA: TMS-AIME, 1988) 275-284

3. G.R. Leverant and M. Gell, "The Influence of Temperature and Cyclic Frequency on the Fatigue Fracture of Cube Oriented Nickel Base Superalloy Single Crystals," Metallurgical Transactions A, 6A, (1975), 367-371

4. K.S. Chan, J.E. Hack and G.R. Leverant, "Fatigue Crack Growth in MAR-M200 Single Crystals," Metallurgical Transactions A, 18A, (1987), 751-759

5. H.H. Johnson, Materials Research Standards, vol. 5, (1965), 442-445

6. Annual Book of ASTM Standards, ASTM E647, ASTM, Philadelphia, PA, (1984), 711-731

7. K.S. Chan and T.A. Cruse, "Stress Intensity Factors for Anisotropic Compact-Tension Specimens with Inclined Cracks," Engineering Fracture Mechanics, vol. 23, no. 5, (1986), 863-874

8. B.H. Kear and B.J. Piearcey, "Tensile and Creep Properties of Single Crystals of the Nickel-Base Superalloy Mar-M 200," Trans. TMS-AIME, 239, (1967), 1209-1215

9. S.M. Copley, B.H. Kear and G.M. Rowe, "The Temperature and Orientation Dependence of Yielding in Mar-M 200 Single Crystals," Mater. Sci. Eng., 10, (1972), $87-91$

10. B.A. Lerch and S.D. Antolovich, "Fatigue Crack Propagation Behavior of a Single Crystalline Superalloy," Metallurgical Transactions A, 21A, (1990), 21692177

11. P.C. Paris and G.C. Sih, "Stress Analysis of Cracks," Fracture Toughness Testing and its Applications, ASTM STP 381, American Society for Testing and Materials, (1964), $30-81$ 